PREHOSPITAL CARE

\title{
Consensus on the prehospital approach to burns patient management
}

\author{
K Allison, K Porter
}

Emerg Med J 2004;21:112-114

Burns patients form a large group of trauma patients cared for by first aiders, ambulance staff, nurses, and doctors before reaching specialist care in hospital. Guidance for these important carers is often poor or confused and this engenders anxiety and detracts from optimal patient care. This paper outlines nine key steps in the initial management of burn patients in the prehospital environment based on current available evidence and a consensus of specialists from all disciplines caring for burns patients. The basis of care should be that simple things should always be performed well.

See end of article for authors' affiliations

......................

Correspondence to: Mr K Allison, Faculty of Pre-hospital Care, Royal College of Surgeons of Edinburgh, Nicolson Street, Edinburgh EH89DW, UK; prehosp@rcsed.ac.uk

Accepted for publication 6 August 2003 n the United Kingdom, burns patients account for about 175000 emergency department attendances and 15000 hospital admissions each year. ${ }^{1}$ Consequently the first aid and prehospital care for this large group of patients is of great importance and yet in the authors' experience, simple things are often not done very well.

In 1998 a national survey revealed 58\% of UK ambulance services had no specific treatment policy for burns patients. ${ }^{2}$ Prehospital carers often feel out of their depth in caring for burns patients, particularly children and there is a lack of teaching and simple, evidence based guidelines.

The Faculty of Pre-hospital Care set out to improve the information available concerning immediate care of the burns patient in simple, unambiguous guidelines, so that any carer (including first aider, ambulance personnel, nurse, or doctor) could administer safe, appropriate care. The process to achieve consensus over these guidelines has taken time and the advice and ratification by all groups that look after burns patients from the point of their injury through to definitive care has been painstakingly followed (table 1 and box 1 ). can form the basis for current prehospital care and that they may be updated as new evidence or arrangements for burns patients are made within the UK (box 2).

\section{SAFE APPROACH}

For all prehospital emergencies, this acronym can be used to remind the carer as to the first priorities in patient care.

- Shout or call for help
It is hoped that the guidelines although basic,
- Assess the scene for dangers to rescuer or patient

- Free from danger

- Evaluate the casualty. ${ }^{3-7}$

\section{STOP THE BURNING PROCESS}

The burning process should be stopped/extinguished and the patient should be removed from the burning source. All burnt clothing should be removed (unless it is stuck to the patient) and any jewellery, which may become constrictive. All items of clothing should be brought in a plastic bag to the hospital for examination. For patients with chemical burns, they may need a longer period of irrigation under tap water and specific information about the chemical concerned should be obtained.

\section{COOL THE BURN WOUND}

There is often confusion over this process and how long it should last for. It is suggested that the ambulance service despatch system will advise the "999" caller to cool the burn area for up to 10 minutes. Cool running tap water is sufficient and ice cold water should not be used. If cooling has been done before their arrival, prehospital carers should cool for another 10 minutes during package and transfer. If the burn area is small $(<5 \%)$ then a cold wet towel can be placed on the burn area, on top of the Clingfilm dressing (see next section), but before wrapping up the whole patient to maintain body warmth beneath the blankets. Delays in transporting the burn patient should be minimised, as should the risk of inducing hypothermia, particularly in children. A helpful reminder is to: "Cool the burn wound but warm the patient". ${ }^{\text {8-31 }}$

\section{DRESSINGS}

Dressings are important to help the patient's pain control and to keep the burnt area clean. The burnt area should be covered with a cellophane type wrap Clingfilm, remembering the possible constricting effect of wrapping; smaller pieces are perhaps better than circumferential sheet. The patient should be wrapped up in blankets or a duvet.

In chemical burns after irrigation/cooling, Clingfilm may theoretically worsen the burn effect, so the affected area should be irrigated thoroughly until pain or burning has decreased and only wet dressings should be used. Care should be taken with the management of powder injuries, which may be worsened with water. If 
Table 1 Process of consensus guidelines

Ambulance service and plastic and burns surgeons questionnaire survey Presentation of data at Trauma UK meeting

Presentation of data at British Burns Association (BBA) meeting Letter in BBA newsletter inviting suggestions and help

Publication: "The UK pre-hospital management of burn patients:

current practice and the need for a standard approach"

Consensus meeting held in Birmingham

Consensus information presented at BBA meetings

Consensus guidelines included in Joint Royal Colleges and Ambulance Liaison Committee (JRCALC)

1998

June 1999

April 2000

September 2000

Burns 2002;28:135-42.

February 2001

April 2001, April 2002

March 2002 available, data regarding the probable chemical should be taken with the patient to hospital. ${ }^{232-38}$

\section{ASSESSMENT AND MANAGEMENT OF IMMEDIATELY OR IMMINENTLY LIFE THREATENING PROBLEMS: AcBC (Airway with cervical spine stabilisation, Breathing, Circulation)}

It should be remembered that the patient may have other injuries coexistent with their burn injury. These should be suspected, diagnosed, and treated as with any other prehospital emergency. The patient should have high flow oxygen delivered via a non-rebreath mask ( $15 \mathrm{ls} / \mathrm{min})$. If a patient has an isolated burn injury that is small and when no inhalation injury is suspected the oxygen may not be necessary. ${ }^{20} 3940$

\section{ASSESSMENT OF BURN SEVERITY}

To estimate the size of the patient's burned area, use the Wallace rule of nines or the "half burnt/half not" approach (serial halves: $>1 / 2,<1 / 2,1 / 4-1 / 2,<1 / 4)$. This latter technique although new, is effective in burn size estimation in prehospital care. Other important features of the burn injury to define are:

- Time of burn injury

Box 1 Individuals and organisations present at the consensus meeting in February 2001

- Ambulance Services (West Midlands, Warwickshire, County Air Ambulance)

- Ambulance Service Association

- Medical directors of three ambulance services

- British Association of Immediate Care Schemes (BASICS) and BASICS education

- Faculty of Pre-hospital Care, Royal College of Surgeons of Edinburgh

- British Burns Association

- Local burns surgeons

- Burns nurses

- Military medical staff

- DERA

- Voluntary aid societies

- Fire services

- Clinical biochemist

- British Association of Accident and Emergency Medicine (BAEM)

- Accident and emergency specialty consultants

- General practitioners
- Mechanism of injury (flame \{clothes or patient caught fire\}, flash burn, scald, electrical, chemical)

- Burn within confined space = possible respiratory inhalation injury

- In children and elderly people, always be mindful of potential non-accidental injury.

It is of paramount importance that the prehospital carer keeps good records. ${ }^{41-44}$

\section{CANNULATION AND INTRAVENOUS FLUIDS}

The emphasis for patient cannulation should be for the administration of titrated opioid analgesia. It is important that cannulation procedures do not unnecessarily extend the on scene time; this should be limited to two attempts only.

Fluid replacement Hartmann's solution (or 0.9\% normal saline if Hartmann's not available) can be started if the patient is cannulated, but must be started for burns $>1 / 4$ TBSA and/or if time to hospital is more than one hour from time of injury. A guide to fluid volumes is:

- (1000 ml for adult, $500 \mathrm{ml}$ for child 10-15 years, $250 \mathrm{ml}$ 5-10 years, no fluids for under $5 \mathrm{~s}$ )

- Care should be taken not to over-infuse small, frail, elderly patients with a history of left ventricular failure (LVF)

- Fluid therapy should ideally be warmed. ${ }^{45-48}$

\section{ANALGESIA}

As previously indicated, analgesia is best accomplished by cooling and covering the burned area. Intravenous opioid can be titrated to make the adult patient more comfortable and should be accompanied by an antiemetic. In children intranasal diamorphine is an option that may be considered. Entonox should only be used when these options are unavailable as it may be difficult to administer, has varying efficacy, and decreases the oxygen delivery. ${ }^{2}{ }^{13} 366^{49-52}$

\section{Box 2 Consensus guidelines}

1. SAFE approach

2. Stop the burning process

3. Cooling

4. Covering/dressing

5. Assessment of $A c B C$

6. Assessment of burn severity

7. Cannulation (and fluids)

8. Analgesia

9. Transport 


\section{TRANSPORT}

All treatment should be carried out with the aim of reducing on-scene times and delivering the patient to the appropriate treatment centre. This should be the nearest appropriate accident and emergency department (A\&E), unless local protocols allow direct transfer to a burns facility.

Communication with A\&E should give the essential information only (age, sex, incident time and mechanism, $\mathrm{ABC}$ problems, relevant treatment, ETA). ${ }^{153-60}$

\section{Authors' affiliations}

K Allison, K Porter, Faculty of Pre-hospital Care, Royal College of Surgeons of Edinburgh, Edinburgh, UK

\section{REFERENCES}

1 National Burn Care Review. National burn care review, 2000. http:// www.baps.co.uk/documents/nbcr.pdf.

2 Allison K. The UK pre-hospital management of burn patients: current practice and the need for a standard approach. Burns 2002;28:135-42.

3 Greaves I, Porter K, eds Scene approach, assessment and safety. Pre-hospital medicine. The principles and practice of immediate care. London: Arnold, 1999:273-9.

4 National Association of Emergency Medical Technicians. Pre-hospital trauma life support manual. Clinton MS: NAEMT, 1994.

5 Greaves IHTPK, ed. Basic life support. In: Emergency care a textbook for paramedics. London: WB Saunders, 1997:17-26.

6 IHCD. Ambulance service paramedic training 3. Bristol: IHCD, 1994

7 IHCD. Ambulance service basic training. Bristol: IHCD, 1991.

8 Nguyen NL, Gun RT, Sparnon AL, et al. The importance of immediate cooling - a case series of childhood burns in Vietnam. Burns 2002;28:173-6.

9 Nguyen NL, Gun RT, Sparnon AL, et al. The importance of initial management: a case series of childhood burns in Vietnam. Burns 2002;28:167-72.

10 Jandera V, Hudson DA, de Wet PM, et al. Cooling the burn wound: evaluation of different modalites. Burns 2000;26:265-70.

11 Sawada $Y$, Urushidate S, Yotsuyanagi T, et al. Is prolonged and excessive cooling of a scalded wound effective? Burns 1997;23:55-8.

12 Lawrence JC. First-aid measures for the treatment of burns and scalds. J Wound Care 1996;5:319-22.

13 Hodson AH. Treating burns by initial cooling. J R Soc Med 1992:85:121.

14 Latariet J. [Immediate cooling with water: emergency treatment of burns]. Pediatrie (Bucur) 1990;45:237-9

15 Lawrence JC. British Burn Association recommended first aid for burns and scalds. Burns, including thermal injury 1987;13:153.

16 Clayton MC, Solem LD. No ice, no butter. Advice on management of burns for primary care physicians. Postgrad Med 1995;97:151-60, 165.

17 Demling RH, Mazess RB, Wolberg W. The effect of immediate and delayed cold immersion on burn edema formation and resorption. J Trauma 1979:19:56-60.

18 Kravitz H. Cooling as first aid for burns. [Letter]. Pediatrics 1974:53:766.

19 Kravitz H. First-aid therapy for burns - cool it: need to instruct laymen. Clin Pediatr (Phila) 1970;9:695-7.

20 Australian and New Zealand Burn Association. Emergency management of severe burns course manual. Sydney: ANZBA, 1996.

21 St John Ambulance, St Andrew's Ambulance Association and the British Red Cross. First aid manual. London: Dorling Kindersley, 1997.

22 Judkins KC. Thermal injury. In: Greaves I, Porter K, eds. Pre-hospital medicine the principles and practice of immediate care. London: Arnold, 1999:375-87.

23 Greaves IHTPK, ed. Burns. In: Emergency care a textbook for paramedics. London: WB Saunders, 1997:270-8.

24 Raine TJ, Heggers JP, Robson MC, et al. Cooling the burn wound to maintain microcirculation. J Trauma 1981;21:394-7.

25 Jelenko C III, Jennings WD Jr, O'Kelley WR III, et al. Threshold burning effects on distant microcirculation: presence of a passively transferrable, nondialyzable arteriolar constrictor substance in blood of burned patients. Am Surg 1974:40:388-91.

26 Jelenko C III, Jennings WD Jr, O'Kelley WR III, et al. Threshold burning effects on distant microcirculation. II. The relationship of area burnt to microvascular size. Arch Surg 1973;106:317-19.
27 Jelenko C III, Jennings WD Jr, O'Kelley WR III, et al. Threshold burning effects on distant microcirculation. I. Preliminary observations. Arch Surg 1971; 102:617-25.

28 King TC, Price PB. Surface cooling following extensive burns. JAMA 1963; 183:677.

29 Ofeigsson OJ. Water cooling: first aid treatment of of scalds and burns. Surgery 1965;57:391.

30 Cooke MW, Morrell R, Wilson S, et al. Does criteria based dispatch of 999 calls adequately detect the critically ill and injured? Pre-hospital Immediate Care 1999:3:191-5.

31 Childs C, Stoner HB, Little RA. Cutaneous heat loss shortly after burn injury in children. Clin Sci (Lond) 1992;83:117-26.

32 O'Rourke G, Hanley K, Dowling J, et al. The use of basic life support kits in general practice. Ir Med J 1999:92:399-400.

33 Kinsella J, Booth MG. Pain relief in burns: James Laing memorial essay 1990. Burns 1991;17:391-5.

34 Vartak AM, Keswani MH, Patil AR, et al. Cellophane-a dressing for splitthickness skin graft donor sites. Burns 1991;17:239-42.

35 Queen D, Evans JH, Gaylor JD, et al. Burn wound dressings - a review. Burns, including thermal injury 1987; 13:218-28.

36 Coats TJ, Edwards C, Newton R, et al. The effect of gel burns dressings on skin temperature. Emerg Med J 2002; 19:224-5.

37 Treharne $\mathrm{U}$, Kay AR. The initial management of acute burns. J R Army Med Corps 2001;147:198-205.

38 Cole RP, Shakespeare PG, Chissell HG, et al. Thermographic assessment of burns using a nonpermeable membrane as wound covering. Burns 1991;17:117-22.

39 American College of Surgeons. Injuries due to burns and cold. In: ACS committee on trauma, ed. Advanced trauma life support for doctors (ATLS). Chicago: ACS, 1997:273-88.

40 Hodgetts T, McNeil I, Cooke M. The pre-hospital emergency management master. London: BMJ, 1995.

41 Ashworth HL, Cubison TC, Gilbert PM, et al. Treatment before transfer: the patient with burns. Emerg Med J 2001;18:349-51.

42 McGugan EA, Paterson B, Nichol N, et al. Re: Accuracy of burn size estimation and subsequent fluid resuscitation prior to arrival at the Yorkshire Regional Burns Unit. A three year retrospective study. Burns 2000;26:415-16.

43 Collis N, Smith G, Fenton OM. Accuracy of burn size estimation and subsequent fluid resuscitation prior to arrival at the Yorkshire Regional Burns Unit. A three year retrospective study. Burns 1999:25:345-51.

44 Hammond JS, Ward CG. Transfers from emergency room to burn center: errors in burn size estimate. J Trauma 1987;27:1161-5.

45 Henry S, Scalea TM. Resuscitation in the new millennium. Surg Clin North Am 1999;79:1259-67, viii.

46 Myers C. Fluid resuscitation. Eur J Emerg Med 1997;4:224-32.

47 Warden GD. Burn shock resuscitation. World J Surg 1992;16:16-23.

48 Dalton A. M. Pre-hospital intravenous fluid replacement in trauma: an outmoded concept? J R Soc Med 1995;4:213-16.

49 Kendall JM, Reeves BC, Latter VS. Multicentre randomised controlled trial of nasal diamorphine for analgesia in children and teenagers with clinical fractures. BMJ 2001;322:261-5.

50 Chambers JA, Guly HR. Prehospital intravenous nalbuphine administered by paramedics. Resuscitation 1994;27:153-8.

51 Phillips GD. First aid in disasters. Med J Aust 1980;2:420-4.

52 Wilson JA, Kendall JM, Cornelius P. Intranasal diamorphine for paediatric analgesia: assessment of safety and efficacy. J Accid Emerg Med 1997; 14:70-2.

53 Cummings G, O'Keefe G. Scene disposition and mode of transport following rural trauma: a prospective cohort study comparing patient costs. J Emerg Med 2000;18:349-54

54 Baack BR, Smoot EC III, Kucan JO, et al. Helicopter transport of the patient with acute burns. J Burn Care Rehabil 1991;12:229-33

55 Novak J, Tury P. [Inter-hospital transportation of burned patients]. Magy Traumatol Orthop Helyreallito Seb 1991;34:43-8.

56 Palmer JH, Sutherland AB. Problems associated with transfer of patients to a regional burns unit. Injury 1987; 18:250-7.

57 Marichy J, Chahir N, Peres-Tassart C, et al. [Prehospital management of burns]. Pathol Biol(Paris) 2002:50:74-81.

58 Nakae $\mathrm{H}$, Wada $\mathrm{H}$. Characteristics of burn patients transported by ambulance to treatment facilities in Akita Prefecture, Japan. Burns 2002;28:73-9.

59 Slater H, O'Mara MS, Goldfarb IW. Helicopter transportation of burn patients. Burns 2002;28:70-2.

60 De Wing MD, Curry T, Stephenson E, et al. Cost-effective use of helicopters for the transportation of patients with burn injuries. J Burn Care Rehabil 2000;21:535-40. 